\title{
Quality of Life of Chronic Hepatitis C Patients Receiving Sovaldi Treatment Regimen at Sharq Almadina Hospital in Alexandria
}

\author{
Nahla Gamaleldin'”, Nagwa Shokeir', Hend H. Abdelaziz², and \\ Heba Elweshahy'
}

${ }^{1}$ Department of Community Medicine, Faculty of Medicine, University of Alexandria, and ${ }^{2}$ Department of Family Medicine, Ministry of Health, Egypt

\begin{abstract}
Background: Hepatitis C virus (HCV) infection is a worldwide public health problem, affecting about 3\% of the world's population. The introduction of sofosbuvir (Sovaldi) markedly changed therapeutic outcomes. The assessment of HRQoL in HCV patients under treatment might help to better understand the effect of treatment on the patient's quality of life. Aim: The study was conducted to assess the quality of life of chronic hepatitis $C$ patients receiving Sovaldi at the outpatient hepatology clinic in Sharq Almadina hospital. Patients and Methods: A cross-sectional survey was conducted among chronic hepatitis $C$ patients receiving Sovaldi treatment regimen for at least 3 months. Data was collected from the studied CHCV patients using face-to-face interviews including personal \& sociodemographic characteristics, The chronic liver disease questionnaire (CLDQ) to assess health-related quality of life, and the translated Arabic version of the short-form (SF 36) generic quality of life questionnaire. In addition, reviewing the medical records of studied CHCV patients to collect data about their laboratory findings was done. Results: More than two-thirds of studied patients (69.1\%) discovered the disease during the National Egyptian Campaign. The overall median value of SF-36Q items was 53.19 indicating a poor HRQoL. There were significant positive correlations between the majority of SF-36Q individual domain scores and that for CLDQ P $<0.001$ as well as the total scores. Conclusions: There were significant positive correlations between the majority of SF-36Q individual domain scores and that for CLDQ as well as the total scores.
\end{abstract}

Keywords: HCV, Sovaldi, Qol

\section{Introduction}

Hepatitis C virus infection (HCV) is a resource-consuming health problem, where there is an increase of $2.8 \%$ in its seroprevalence over the previous years, accounting for about 185 million cases $^{(1)}$. HCV can lead to acute and chronic infections, its severity ranges from mild disease for a few weeks to a severe lifetime illness. Acute HCV infection is asymptomatic in most cases and is only- very rarely- associated with serious disease. Within 6 months of infection, around $34 \%$ of patients recovered spontaneously without treatment. The remaining patients develop chronic HCV infection ${ }^{(2)}$. 
Globally, viral hepatitis was ranked as the $7^{\text {th }}$ leading cause of mortality. With hepatitis $C$ virus is responsible for around half of this mortality(3). Egypt is one of the most affected countries by HCV. World Health Organization (WHO) has classified Egypt as having the highest prevalence of Hepatitis C virus worldwide, with about $20 \%$ of blood donors testing positive for HCV. Egypt has the highest hepatitis $C$ prevalence with thousands of people dyin yearly due to major liver complications like liver failure and liver cancer ${ }^{(4,5)}$. Two-thirds of seropositive Egyptian patients are chronically infected and need treatment ${ }^{(6)}$. Even though the historical anti-Schistosoma parenteral treatment campaigns were accused of this high prevalence of HCV, around two-thirds of the positive cases nowadays acquired the infection from healthcare settings $(7)$. The prevalence of HCV antibodies among adults $15-59$ years is $14.7 \%$ in 2009 and $10.0 \%$ in 2015 according to the Egyptian Demographic and Health Surveys (EDHS)(7). Lowering of the prevalence of seropositivity might be due to population aging, improved infection control practices as well as the availability of directly acting antiviral drugs. In addition to migration and death of HCV-positive persons ${ }^{(8)}$. Mostly, patients with chronic HCV infection need antiviral medications. The first aim of treatment is clearance of infection, and finally sustained virological response (SVR). Six months after the beginning of treatment HCV-RNA counts that reach less than 50 international units per milliliter; may show sustained treatment with recurrence only in about $5 \%$ of patients $(9,12)$. Therefore, with increased morbidity and mortality associated with CHCV infection, it is critical to achieving viral clearance associated with significantly reduced rates of liver failure, progression of fibrosis, and liver-related deaths among CHCV patients(13). Globally, the development of direct-acting antiviral
(DAA) agents, has transformed the treatment of HCV infection. These DAA targets viral proteins and cellular processes that are essential to viral replication ${ }^{(14)}$. The HCV Model of Care (MOC) was established in 2006 through the National Committee for Control of Viral Hepatitis (NCCVH) to design a national strategic plan to control $\mathrm{HCV}$ infection. This plan demonstrates policies and procedures for patient care service delivery. The Egyptian initiative campaign of national treatment for viral hepatitis is considered one of the most fruitful and effective public health initiatives worldwide. The NCCVH showed success to implement a robust strategy to control viral hepatitis in Egypt ${ }^{(9)}$. Once the DAA was registered in Egypt, the Ministry of State for Administrative Development developed a web-based online registration system (www.nccvh.org.eg) $)^{(10,11)}$. Health-related quality of life (HRQoL) is the patients' perception of the disease's effect on their daily life, as well as their psychological and social well-being. Therefore, it is used as the gold standard to measure patients' own experiences with their disease journey ${ }^{(15)}$. While antiviral treatment can improve the rate of liver-related deaths, associated side effects can have a negative impact on $\mathrm{HRQOL}^{(16)}$. The previous anti-HCV treatment with interferon and ribavirin had a further negative impact on patients' HRQoL due to substantial side effects. Well evidenced side effects of interferon are often described as an influenza-like episode, including fever, myalgia, and headache. Interferon (IFN)-mediated bone marrow suppression can produce pancytopenia. Neurological, psychological, and gastrointestinal manifestations were documented ${ }^{(17,18)}$. There have been no studies to date on how Egyptian HCV patients who have received the new DAAs feel about their HRQoL. As a result, this is the first study to assess a variety of patient-related outcomes (PROs), such as 
health-related quality of life (HRQoL), physical, mental health status (i.e., depression, anxiety, and stress), and perceived social support, among HCV patients receiving new DAAs therapy regimens, either interferonfree or interferon-containing regimen. The purpose of this manuscript was to assess the health-related quality of life of chronic hepatitis $C$ patients receiving Sovaldi containing regimen in terms of physical, mental, and social functioning in Sharq Almadina hospital.

\section{Patients and Methods}

This cross-sectional study was carried out on 165 HCV patients receiving Sovaldi treatment. Chronic hepatitis C patients above 18 years of age of both genders who received oral Sovaldi containing regimen (Sofosbuvir $400 \mathrm{mg}$ and daclatasvir $60 \mathrm{mg}$ once daily) for at least three months (12 weeks) and agreed to participate in the study were included. While Patients with adjuvant hepatitis $B$ virus (HBV) infection and those who have liver cirrhosis, hepatocellular carcinoma, or chronic liver diseases of other causes were excluded from the study. A minimum sample of 165 chronic hepatitis $C$ patients receiving Sovaldi is needed to assess their quality of life using CLDQ (chronic liver disease questionnaire) based on Chang et al 2014 ${ }^{(18-20)}$. The sample size was estimated using PASS program version 20 at $\% 5$ level of significance and $80 \%$ power ${ }^{(18-21)}$. A systematic random sampling method was used to obtain the required sample during the period of the fieldwork.

\section{Data collection tools}

A. Patient interview: All patients in the study were interviewed to collect data using

- A structured interview format: it included data about patients' personal and socio-demographic characteristics, their medical and family history as well as detailed treatment history for hepatitis $C$ infection namely history of receiving Sovaldi injection before oral Sovaldi, the timing of receiving oral Sovaldi containing regimen, treatment adherence, side effects of medications and perceived improvement after treatment.

- The chronic liver disease quality of life questionnaire (CLDQ): It is an instrument that is disease-specific, used for measuring health-related quality of life (HRQoL) in patients with chronic liver disease (CLD). The questionnaire consists of six domains namely Abdominal Symptoms (AS) 3 items, Fatigue (FA) 5 items, Systemic Symptoms (SS) 5 items, Activity (AC) 3 items, Emotional Function (EF) 8 items, and Worry (WO) 5 items with a total score of 29 items. The chronic liver disease questionnaire (CLDQ) was the first liver-specific questionnaire developed in $1999^{(19,22,23)}$. It has been translated into many languages for cross-cultural use and proved to be a successful and valid tool for HRQOL measurement in patients with chronic liver disease. The Arabic form was used. A score was measured for each item, and the scores ranged from 1 (the most impaired) to 7 that had the least symptoms, indicating a good prognosis. The total score was calculated as the average of the 29 domains obtaining a total score ranging from 1 to 7 .

- The translated Arabic version of the short-form (SF-36) generic quality of life questionnaire ${ }^{(24)}$ : The SF-36 questionnaire consists of eight scales 
- namely physical functioning (10 items), role-physical (4 items), bodily pain ( 2 items) health ( 5 items), vitality ( 4 items), social functioning ( 2 items), role-emotional (3 items), and mental health ( 5 items). In addition to a single item that indicates perceived change in health. Scoring of the questionnaire was done in two steps:

Step I: All questions were scored on a numeric scale using a scoring key. All items are scored so that a high score defines a more favorable health state. Then each item is scored on a 0 to 100 scale (transformed score)

Step II: The scores from those items that express each domain of functional health state are then averaged, for a final score for each of the 8 dimensions assessed.

- Record review: Reviewing the medical records of studied chronic hepatitis $C$ patients to obtain their data at the beginning of treatment and the results of laboratory investigations including baseline investigations and those at 12 weeks after starting Sovaldi treatment namely liver function tests and complete blood count. In addition to the results of the PCR test (HCV- RNA counts).

A pilot study was carried out to test the data collection tools, assess the feasibility of data collection, and estimate the average time needed for collecting the data. It included 15 patients. Their data were not included in the final data for analysis.

\section{Ethical Considerations}

An informed verbal and written consent was obtained from all studied patients after explaining the nature, steps, and aim of the study. Patients were informed that participation is voluntary and patients' right for refusing participation was respected. Privacy and confidentiality of data obtained were ensured all through the conduction of the research. The study was conducted after approval of the Medical Ethics Committee of Alexandria Faculty of Medicine.

\section{Statistical Analysis}

IBM SPSS software package version 20.0. (Armonk, NY: IBM Corp) was used for the analysis of data. The Kolmogorov-Smirnov test was used to test the normality of distribution. Quantitative data were described using range (minimum and maximum), mean, standard deviation if were normally distributed however median and interquartile range (IQR) were used to describe variables that were not normally distributed. Significant results were made when the $p$-value was less than $5 \%$.

\section{Results}

\section{Sociodemographic characteristics of $\mathrm{CHCV}$ patients}

As regard gender, more than half of all studied CHCV patients (58.8\%) were females, while just more than two-fifths of them $(41.2 \%)$ were males. Concerning the age of the studied $\mathrm{CHCV}$ patients, it ranged from 23.0 to 70.0 years, with a mean age of $49.29 \pm 14.12$ years, less than one-third of them (29.7\%) were $\geq 60$ years, near to a quarter of $\mathrm{CHCV}$ patients (24.2 \%) were 50$<60$ years, one fifth (20.0\%) were $40-<50$ years, $(13.9 \%)$ were $<30$ years and $(12.1 \%)$ were $30-<40$ years. The mean age of female patients was lower than that of male patients $(47.26 \pm 13.89$ years and 52.19 \pm 14.02 years respectively, $p=0.010$, (Table 1). The majority of the studied CHCV patients, $(81.2 \%)$ lived in urban areas. Insignificantly, there was a slightly higher proportion of male patients who were living in urban areas than female patients $(86.8 \%$ and 
$77.3 \%$ respectively, $\mathrm{p}=0.126)$. Concerning the level of education, around half of stud ied CHCV patients (50.9\%) were illiterate/ read and write, $22.4 \%$ had secondary education, $17.0 \%$ had basic education, and $9.7 \%$ had a university education and above.

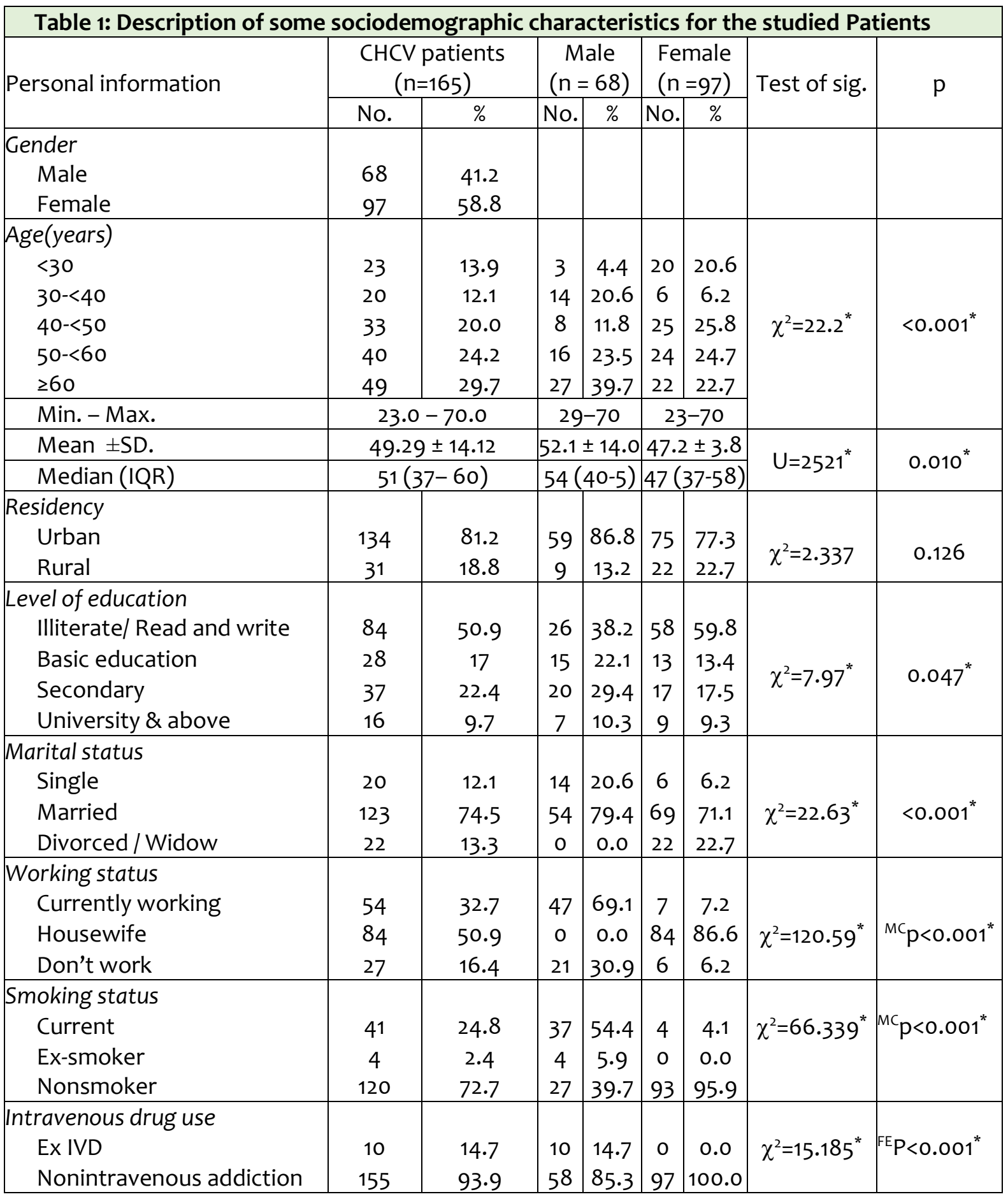

A higher proportion of female patients (59.8\%) was illiterate/ read and write compared to male patients in this aspect
(38.2\%, $\mathrm{p}=0.047$ ). Marital status showed that $12.1 \%$ were single and $13.3 \%$ were divorced / Widow. A significantly slightly 
higher proportion of male patients were married compared to married female patients (79.4\% and $71.1 \%$ respectively). All the divorced/ widow patients (13.3\%) were among females. Single male patients showed a higher proportion than single female patients $(20.6 \%$ and $6.2 \%$ respectively). Differences between male and female patients were statistically significant $(P<0.001)$. Concerning the working status about half of $\mathrm{CHCV}$ patients (50.9\%) were housewives, one-third of them were currently working (32.7\%) and (16.4\%) did not work. Most male patients (69.1\%) were currently working compared to (7.2\%) of cur- rently working female patients $(p=<0.001)$.

Lifestyle habits of $\mathrm{CHCV}$ patients

About three-fourths of CHCV patients (72.7\%) were non-smokers, around a quarter $(24.8 \%)$ were current smokers and only (2.4\%) were ex-smokers. A significantly higher proportion of male patients were currently smoking than female patients ( $54.4 \%$ and $4.1 \%$ respectively, $\mathrm{p}<0.001$ ). Furthermore, a minority of $\mathrm{CHCV}$ patients (14.7\%) were ex- intravenous drug addicts. All the female patients (100\%) were nonintravenous drug addicts compared to $85.3 \%$ of male patients $(p<0.001)$ (Table 1$)$.

\begin{tabular}{|l|c|c|c|}
\hline \multicolumn{3}{|c|}{ Table 2: Distribution of chronic HCV patients according to scores of CLDQ $(\mathbf{n}=\mathbf{1 6 5})$} \\
\hline \multirow{2}{*}{ CLDQ items } & \multicolumn{3}{|c|}{ All studied chronic HCV patients $\mathrm{n}=165$} \\
\cline { 2 - 4 } & Min. - Max. & Mean \pm SD. & Median (IQR). \\
\hline Abdominal symptoms (AS) & $1.0-7.0$ & $4.49 \pm 1.88$ & $5.0(3.0-6.0)$ \\
\hline Fatigue (FA) & $1.0-7.0$ & $4.41 \pm 1.55$ & $4.6(3.0-5.6)$ \\
\hline Systemic symptoms (SS) & $1.0-7.0$ & $5.05 \pm 1.46$ & $5.4(4.2-6.2)$ \\
\hline Activity (AC) & $2.33-7.0$ & $5.81 \pm 1.46$ & $6.7(4.7-7.0)$ \\
\hline Emotional Function (EF) & $1.0-7.0$ & $4.48 \pm 1.56$ & $4.8(3.3-5.6)$ \\
\hline Worry (WO) & $1.0-7.0$ & $3.64 \pm 2.36$ & $3.2(1.0-6.2)$ \\
\hline Overall CLDQ & $\mathbf{1 . 6 7 - 7 . 0}$ & $\mathbf{4 . 5 9 \pm 1 . 2 8}$ & $\mathbf{4 . 7 ( 3 . 8 - 5 . 4 )}$ \\
\hline
\end{tabular}

2. Quality of life of chronic liver disease patients receiving sovaldi treatment using CLDQ and SF36 questionnaire

Table (2) shows that the overall mean value of CLDQ items was $(4.59 \pm 1.28)$ indicating fair HRQoL. The highest mean value (best HRQoL) was for activity domain ( 5.81 \pm 1.46 ), followed by a mean value of systemic symptoms $(5.05 \pm 1.46)$, then nearly similar mean value, of abdominal symptoms (4.49 \pm 1.88$)$, emotional function $(4.48 \pm 1.56)$ and fatigue domains (4.41 \pm 1.55). The lowest mean value (worst HRQoL) was for the worry domain (3.64 \pm 2.36). The overall mean score of CLDQ for male patients was insignificantly slightly higher than that for female patients (4.64 \pm 1.37 and $4.55 \pm 1.22$ respectively), $\mathrm{P}=$ 0.640 . Moreover, the overall mean score value was the highest (better HRQoL) for those patients in the age group 50- $<60$ years $(4.77 \pm 1.18)$. It was nearly equal to those of the age group 30-<40 years and $<30$ years $(4.71 \pm 1.33$ and $4.70 \pm 1.28$ respectively). The lowest mean score (poor HRQoL) $(4.25 \pm 1.13)$ was noticed among the age group $40-<50$ years. These results were found to be statistically insignificant, $P=0.474$. Table (3). Concerning residency, insignificantly the overall mean score of CLDQ was found to be slightly higher for those patients who were living in urban $(4.60 \pm 1.27)$ than those who were living in rural $(4.54 \pm 1.34), P=0.810$. 


\begin{tabular}{|c|c|c|c|c|c|c|}
\hline Table 3: The or & erall & $\begin{array}{l}\text { LDQ mean s } \\
\text { rronic HCV p }\end{array}$ & $\begin{array}{l}\text { re and socio } \\
\text { ents }(n=16\end{array}$ & ographi & ta of & \\
\hline Parameter & & overall CLL & mean score $\mathrm{C}$ & patients & Test of & \\
\hline Parameter & $\mathrm{N}$ & Min. - Max. & Mean \pm SD. & Median & Sig. & $P$ \\
\hline Gender & & & & & & \\
\hline Male & 68 & $1.67-6.54$ & $4.64 \pm 1.37$ & 4.77 & & \\
\hline Female & 97 & $1.67-7.0$ & $4.55 \pm 1.22$ & 4.50 & $t=0.468$ & 0.640 \\
\hline Age (years) & & & & & & \\
\hline$<30$ & 23 & $2.63-7.0$ & $4.70 \pm 1.28$ & 4.58 & & \\
\hline $30-<40$ & 20 & $2.63-6.54$ & $4.71 \pm 1.33$ & 4.75 & & \\
\hline $40-<50$ & 33 & $1.67-6.29$ & $4.25 \pm 1.13$ & 4.25 & $F=0.885$ & 0.474 \\
\hline $50-<60$ & 40 & $1.67-7.0$ & $4.77 \pm 1.18$ & 4.79 & & \\
\hline$\geq 60$ & 49 & $1.67-7.0$ & $4.57 \pm 1.42$ & 4.67 & & \\
\hline Residency & & & & & & \\
\hline Urban & 134 & $1.67-7.0$ & $4.60 \pm 1.27$ & 4.67 & $t-0>211$ & 810 \\
\hline Rural & 31 & $1.67-7.0$ & $4.54 \pm 1.34$ & 4.42 & $\tau=0.241$ & 0.810 \\
\hline Living alone & & & & & & \\
\hline Yes & 21 & $1.67-7.0$ & $4.36 \pm 1.42$ & 4.25 & & \\
\hline No & 144 & $1.67-7.0$ & $4.62 \pm 1.26$ & 4.67 & $t=0.866$ & 0.388 \\
\hline Level of education & & & & & & \\
\hline Illiterate/ Read and write & 84 & $1.67-7.0$ & $4.58 \pm 1.35$ & 4.50 & & \\
\hline Basic education & 28 & $1.67-6.54$ & $4.56 \pm 1.47$ & 4.46 & & \\
\hline Secondary & 37 & $1.83-6.33$ & $4.61 \pm 1.10$ & 4.75 & $F=0.018$ & 0.997 \\
\hline University \& above & 16 & $3.21-6.29$ & $4.64 \pm 0.98$ & 4.63 & & \\
\hline Marital status & & & & & & \\
\hline Single & 20 & $1.83-7.0$ & $4.95 \pm 1.59$ & 5.33 & & \\
\hline Married & 123 & $1.67-7.0$ & $4.56 \pm 1.23$ & 4.67 & $F=1.060$ & 0.349 \\
\hline Divorced / Widow & 22 & $1.67-7.0$ & $4.40 \pm 1.22$ & 4.25 & & \\
\hline Working status & & & & & & \\
\hline Currently working & 54 & $1.67-6.33$ & $4.43 \pm 1.29$ & 4.63 & & \\
\hline Housewife & 84 & $1.67-7.0$ & $4.61 \pm 1.24$ & 4.50 & $F=0.931$ & 0.396 \\
\hline Don't work & 27 & $1.83-6.54$ & $4.84 \pm 1.38$ & 5.0 & & \\
\hline Income & & & & & & \\
\hline 500-1000 LE & 11 & $3.46-7.0$ & $4.94 \pm 1.01$ & 5.0 & & \\
\hline 1000-1500 LE & 84 & $1.67-7.0$ & $4.63 \pm 1.33$ & 4.63 & $F=0.674$ & 0.511 \\
\hline More than 2000 LE & 70 & $1.67-6.54$ & $4.49 \pm 1.25$ & 4.63 & & \\
\hline Smoking & & & & & & \\
\hline Current smoker & 41 & $1.67-6.54$ & $4.53 \pm 1.42$ & 4.58 & & \\
\hline Ex-smoker & 4 & $4.50-6.33$ & $5.54 \pm 0.94$ & 5.67 & $F=1.164$ & 0.315 \\
\hline Nonsmoker & 120 & $1.67-7.0$ & $4.58 \pm 1.23$ & 4.63 & & \\
\hline IV drug addiction & & & & & & \\
\hline Ex-IV addict & 10 & $2.63-6.54$ & $4.92 \pm 1.55$ & 5.48 & 858 & \\
\hline Non-IV addict & 155 & $1.67-7.0$ & $4.57 \pm 1.26$ & 4.58 & $t=0.858$ & 0.392 \\
\hline
\end{tabular}

The overall mean score for patients who were living alone $(4.36 \pm 1.4)$ was in signifi- cantly lower than those who were not living alone (4.62 \pm 1.2$), p=0.38$ (table 3). 
Table 4: The overall CLDQ mean score and Sovaldi treatment in CHCV patients $(n=165)$

\begin{tabular}{|c|c|c|c|c|c|c|}
\hline \multirow{2}{*}{ Parameter } & \multirow{2}{*}{$\mathrm{N}$} & \multicolumn{3}{|c|}{ overall CLDQ mean score of CHCV patients } & \multirow{2}{*}{$\mathrm{t}$} & \multirow{2}{*}{$P$} \\
\hline & & Min. - Max. & Mean \pm SD. & Median & & \\
\hline \multicolumn{7}{|l|}{ SVR $(H C V-R N A<50 \mathrm{IU} / \mathrm{mL})$} \\
\hline Yes & 161 & $1.67-7.0$ & $4.61 \pm 1.27$ & 4.67 & \multirow{2}{*}{1.601} & \multirow{2}{*}{0.111} \\
\hline No & 4 & $1.67-5.04$ & $3.58 \pm 1.40$ & 3.81 & & \\
\hline \multicolumn{7}{|l|}{ History of SOVALDI injection } \\
\hline Yes & 7 & $2.75-5.38$ & $4.31 \pm 0.96$ & 4.13 & \multirow[b]{2}{*}{0.590} & \multirow{2}{*}{0.556} \\
\hline No & 158 & $1.67-7.0$ & $4.60 \pm 1.29$ & 4.67 & & \\
\hline \multicolumn{7}{|l|}{$\begin{array}{l}\text { Improvement after SOVALDI } \\
\text { injection }\end{array}$} \\
\hline Yes & 3 & $2.75-4.88$ & $3.78 \pm 1.06$ & 3.71 & \multirow[b]{2}{*}{1.353} & \multirow[b]{2}{*}{0.234} \\
\hline No & 4 & $3.96-5.38$ & $4.71 \pm 0.77$ & 4.75 & & \\
\hline \multicolumn{7}{|l|}{$\begin{array}{l}\text { Poor adherence to intake of } \\
\text { oral SOVALDI }\end{array}$} \\
\hline Yes & 31 & $1.67-6.54$ & $4.59 \pm 1.42$ & 4.75 & \multirow[b]{2}{*}{0.001} & \multirow[b]{2}{*}{0.999} \\
\hline No & 134 & $1.67-7.0$ & $4.59 \pm 1.25$ & 4.58 & & \\
\hline \multicolumn{7}{|l|}{ Regular follow up visits } \\
\hline Yes & 151 & $1.67-7.0$ & $4.59 \pm 1.23$ & 4.58 & \multirow{2}{*}{0.026} & \multirow{2}{*}{0.979} \\
\hline No & 14 & $1.67-6.54$ & $4.58 \pm 1.76$ & 4.77 & & \\
\hline \multicolumn{7}{|l|}{$\begin{array}{l}\text { Compliance with the dietary } \\
\text { recommendations }\end{array}$} \\
\hline Yes & 146 & $1.67-7.0$ & $4.57 \pm 1.23$ & 4.58 & \multirow{2}{*}{0.583} & \multirow{2}{*}{0.561} \\
\hline No & 19 & $1.67-6.54$ & $4.75 \pm 1.62$ & 5.0 & & \\
\hline \multicolumn{7}{|l|}{$\begin{array}{l}\text { Side effects of oral sovaldi } \\
\text { treatment }\end{array}$} \\
\hline Yes & 69 & $1.67-7.0$ & $4.74 \pm 1.15$ & 4.75 & \multirow{2}{*}{1.257} & \multirow{2}{*}{0.211} \\
\hline No & 96 & $1.67-7.0$ & $4.48 \pm 1.36$ & 4.46 & & \\
\hline \multicolumn{7}{|l|}{$\begin{array}{l}\text { Psychological support from } \\
\text { HC provider }\end{array}$} \\
\hline Yes & 73 & $1.67-7.0$ & $4.63 \pm 1.22$ & 4.67 & \multirow{2}{*}{0.343} & \\
\hline No & 92 & $1.67-7.0$ & $4.56 \pm 1.33$ & 4.58 & & 0.732 \\
\hline $\begin{array}{l}\text { Psychological and social sup- } \\
\text { port from family members }\end{array}$ & & & & & & \\
\hline Yes & 140 & $1.67-7.0$ & $4.57 \pm 1.28$ & 4.58 & & \\
\hline No & 25 & $1.83-6.54$ & $4.67 \pm 1.26$ & 4.75 & 0.337 & 0.737 \\
\hline $\begin{array}{l}\text { Health education from } \mathrm{HC} \\
\text { providers }\end{array}$ & & & & & & \\
\hline Yes & 71 & $1.67-7.0$ & $4.59 \pm 1.17$ & 4.67 & & 000 \\
\hline No & 94 & $1.67-7.0$ & $4.59 \pm 1.36$ & 4.63 & 0.039 & 0.969 \\
\hline $\begin{array}{l}\text { GH improvement compared } \\
\text { to previous } 6 \text { mos }\end{array}$ & & & & & & \\
\hline Improved & 103 & $1.67-7.0$ & $4.53 \pm 1.28$ & 4.58 & 87 & \\
\hline Not improved & 62 & $1.83-7.0$ & $4.69 \pm 1.29$ & 4.75 & 0.821 & 0.413 \\
\hline
\end{tabular}

Regarding the level of education. The overall mean score of CLDQ was insignificantly the highest for patients who had a university education and above $(4.64 \pm 0.98)$ and the low 
est for patients who had basic education ( $4.56 \pm 1.47), P=0.997$. However, the overall mean score value of CLDQ was insignificantly the highest for the single patients (4.95 \pm 1.59$), P=0.349$ The overall mean score value of CLDQ was higher for patients who do not work $(4.84 \pm 1.38)$ than for housewives $(4.61 \pm 1.24)$ and currently working patients $(4.43 \pm 1.29)$. Furthermore, The overall mean score of CLDQ was the highest for patients who had income from 500-1000 pounds/ monthly (4.94 \pm 1.01) and the lowest for those whose income was more than 2000 pounds/ monthly $(4.49 \pm 1.25)$. These results were found to be statistically insignificant (Table 3). Table 3 indicates that the overall mean score of CLDQ was insignificantly the lowest for currently smoking patients (4.53 \pm 1.42) and the highest for Ex-smokers patients ( $5.54 \pm 0.94), P=0.315$. However, the overall mean score of Ex-intravenous drug addiction patients was insignificantly higher than non-intravenous drug addiction patients $(4.92 \pm 1.55$ and $4.57 \pm 1.26$ respectively), $P=0.392$. Table 3 illustrates that The overall mean score value was insignificantly higher for patients who had other associated chronic diseases $(4.84 \pm 1.23)$ than for patients without associated chronic diseases (4.44 \pm 1.29$), P=0.055$. however, the overall mean score value was insignificantly the lowest for the patients whose duration of disease was <5years $(4.54 \pm 1.29)$ and the highest for patients with a duration of $\geq 10$ years $(5.03 \pm 1.30)$, $\mathrm{P}=0.392$. The overall mean score value was insignificantly lower for those who had a history of complications related to the disease before starting treatment $(4.48 \pm 1.21)$ than those who did not have any complications $(4.88 \pm 1.42), P=0.071$. The overall mean score value was lower for patients with a history of receiving SOVALDI injection $(4.31 \pm 0.96)$ than for those who were $b$ not receiving it $(4.60 \pm 1.29)$. Furthermore, the overall mean score value of patients who felt improvement after SOVALDI injection $(3.78 \pm 1.06)$ was lower than for those who did not feel improvement (4.71 \pm $0.77)$. These results were found to be statistically insignificant. table (4). The overall mean score value of CLDQ was insignificantly nearly equal for those who had poor adherence to intake of oral SOVALDI treatment and those who did not have (4.59 \pm 1.42 and $4.59 \pm 1.25$ respectively), $P=0.999$. However, the overall mean score value was insignificantly slightly higher for regular follow-up visits patients $(4.59 \pm 1.23)$ than irregular follow-up visits one (4.58 \pm 1.76), $P=0.979$ (Table 4). Concerning compliance to dietary recommendations, insignificantly the overall mean score was lower for compliance patients $(4.57 \pm 1.23)$ than for non-compliance one(4.75 \pm 1.62), $\mathrm{P}=0.561$. The overall mean score value of CLDQ was insignificantly higher for patients who had oral SOVALDI regimen side effects $(4.74 \pm 1.15)$ than those without side effects $(4.56 \pm 1.33), P=0.211$. Patients who had psychological support from health care providers showed a slightly higher overall mean score value of CLDQ than those who did not have such support ( 4.63 \pm 1.22 and $4.56 \pm 1.33$ respectively), $P$ $=0.732$. Furthermore, the overall mean score of CLDQ was slightly lower for patients who had psychological and social support from family members $(4.57 \pm 1.28)$ than those who did not have $(4.67 \pm 1.26)$. These results were found to be statistically insignificant, $P=0.737$. Table (4). The overall mean score value of CLDQ was insignificantly almost equal for patients who received health education about the disease from health care providers and those who did not receive health education about the disease, $p=0.969$.

Description of SF36 questionnaire total and domain scores among studied patients: 
Figure (1) shows that the overall median value of SF-36Q items was 53.19 indicating a poor HRQoL. Regarding the various domain items of the SF-36Q, role limitations due to emotional problems recorded the highest median value (100.0) among all studied CHCV patients followed by the median value of physical functioning (80.0), social functioning (75.0), health change
(75.0) and pain (65.0). All these values indicate good $\mathrm{HRQ}$ oL in these domains. On the other hand, the studied patients recorded the lowest median values in the following domains: energy/fatigue (40.0), emotional well-being (48.0), role limitations due to physical health, and general health perception equally (50.0 each). These values indicated poor HRQoL in these domains.

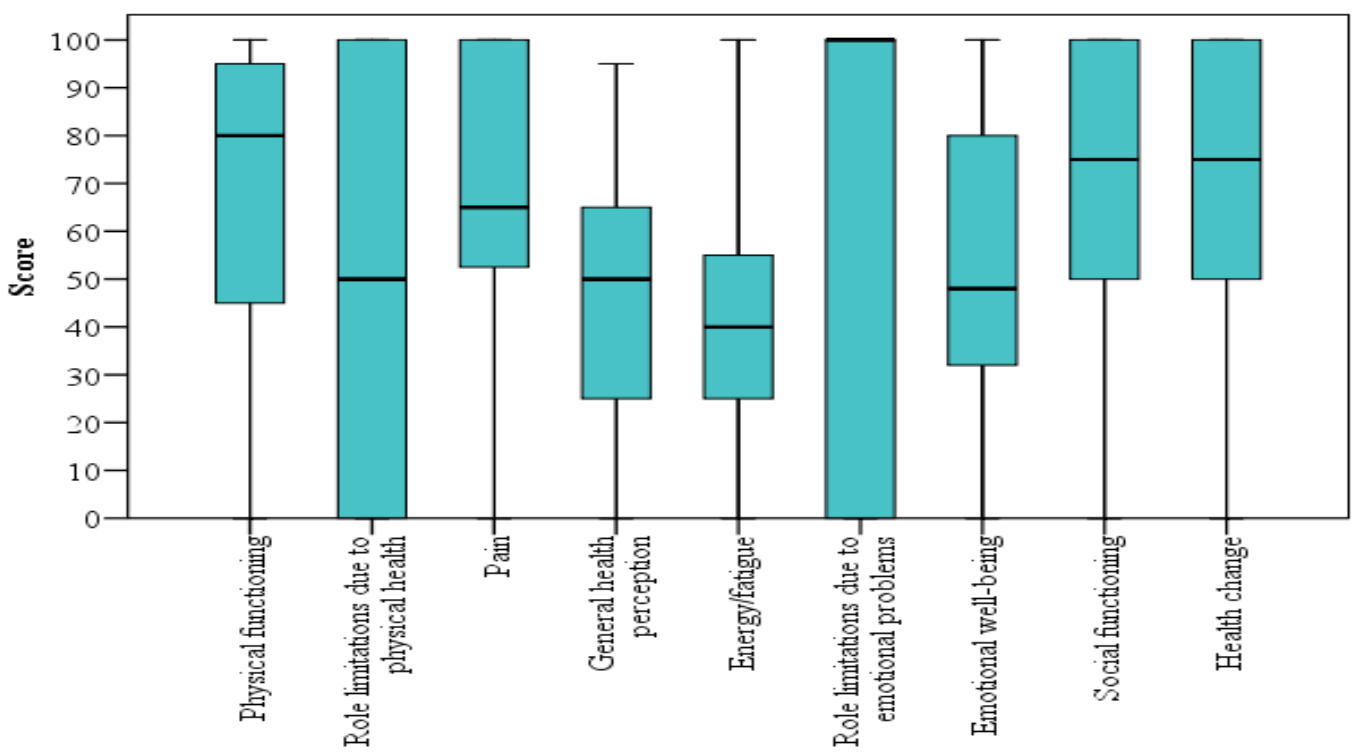

Figure 1: Distribution of studied chronic HCV patients according to domain scores of SF 36 questionnaire

B. Correlation between overall scores and various domains scores of SF-36Q items and CLDQ items of studied CHCV patients.

Figure (2) presents that there were significant positive correlations between the majority of SF-36Q individual domain scores and that for CLDQ $\mathrm{P}<0.001$ as well as total scores. The correlation between SF-36Q health change domain score with CLDQ overall scores and of abdominal symptoms, fatigue, systemic symptoms, and emotional function domains scores was found to be insignificant. Moreover, the magnitude of the correlation between the FA and EF subscales of CLDQ and SF-36Q scales was the highest.

\section{Discussion}

Health-related quality of life (HRQoL) can be used to assess patients' psychological, social, and physical well-being. Previous studies had shown that assessing HRQOL is of utmost importance to community health. It was reflected to be the gold standard to report pay papatients'xperiences with both illness and treatment ${ }^{(25-29)}$. $\mathrm{HRQ}$ oL is an idea related to a person's subjective perception of his health in daily life.s. Moreover, It helps understand their expectations, concerns, aims, and living standards ${ }^{(28)}$. The current study involved 165 papatientsuffering from HCV. Concern 
ing the socio-demographic characteristics of the enrolled patients, as regards gender the present study revealed that more than half of all studied CHCV patients (58.8\%) were females.

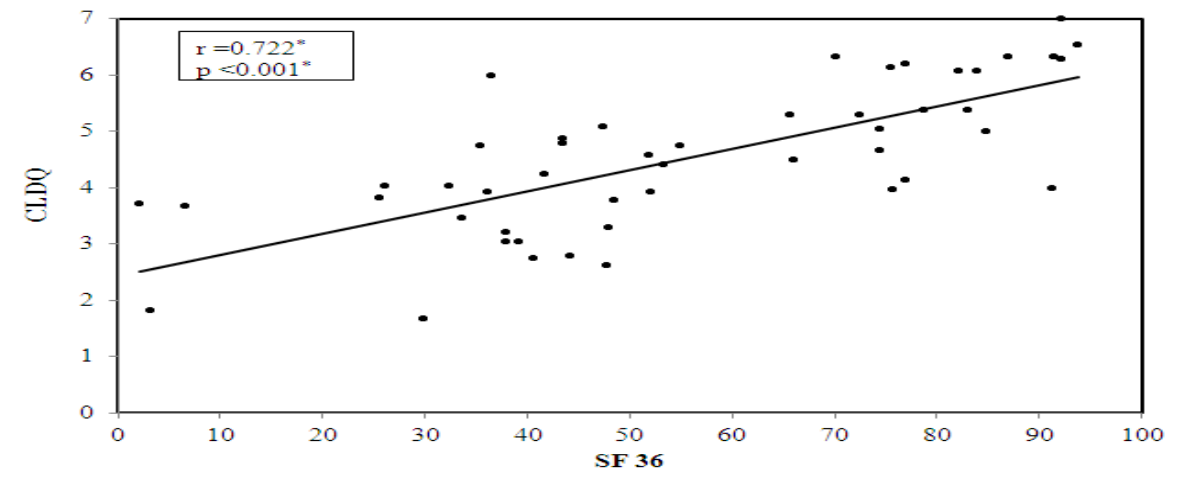

Figure2: Correlation between SF-36Q items' scores with CLDQ items scores of studied chronic HCV patients

These results were in agreement with a study conducted in China that showed that a total of $67.5 \%$ of the subjects were females ${ }^{(27)}$. While it was inconsistent with a study carried out by Gamaleldin et al,(2016) $)^{(28)}$ in Alexandria, Egypt in which the overall prevalence of anti-HCV-positive patients was higher among males (11.3\%) than females (6.5\%). Regarding residency, the majority of the studied $\mathrm{CHCV}$ patients, (81.2\%) lived in urban areas. This is nearly consistent with a study conducted in Canada that showed that the majority of HCV cases (76.3\%) referred to their center lived in urban areas ${ }^{(9)}$. And with that study done by Gamaleldin et al,(2016)(28) at Alexandria university showed that the prevalence of anti-HCV positive infection in urban areas was slightly higher (0.21\%) than in rural areas (0.05\%). On the contrary HCV prevalence in Egypt showed unequal geographic distribution, with the rural areas showing higher prevalence compared to urban sites, and in lower Egypt compared to the rest of the country(30). The parenteral anti-schistosomal treatment (PAT) initiatives were recognized to be the major risk factor for this high prevalence of HCV in rural Egypt among elder patients(30). Also, another study conducted in China signifying that chronic viral hepatitis is more commonly seen in the rural areas than the urban areas of China ${ }^{(27)}$. HCV infection is a social disease with about two-thirds of HVC positive individuals living in developing countries ${ }^{(1)}$. The HCV epidemic in Egypt is socioeconomic. It is mostly prevalent among lower social and economic segments of the population ${ }^{(11)}$. Furthermore, a minority of studied CHCV patients (14.7\%) were ex- intravenous drug addicts. These results contradict that of a cohort's study in Canada which showed that intravenous drug intake was the most reported risk factor for HCV infection (61.1\%), followed closely by intra-nasal drug intake (59.4\%). Tattoos, high-risk sexual activity, and incarceration accounted for $47.8 \%, 44.8 \%$ and $40.2 \%$, respectively ${ }^{(9)}$. However, Illicit drug users (IUDs), having an IUD partner, alcohol and tattooing constituted higher risks in Egypt than in her countries ${ }^{(12)}$. Regarding ways of discovery of the disease, more 
than two-thirds of studied $\mathrm{CHCV}$ patients (69.1\%) discovered the disease during the National Egyptian Campaign, while the west proportions discovered the disease either through accidental investigations or during analyzing job requirements or by the appearance of symptoms (13,3\%,10.9\%, and $6.7 \%$ respectively). Results of the current study were consistent with a previous study that reported that discovery of HCV infection in Egypt is usually by chance or after being symptomatic due to liver disease appear. About 3\% of the patients have been diagnosed actively ${ }^{(12)}$. These Egyptian initiative plans are assumed to have led to this increased HCV seropositive rates nowadays in the Nile Delta. There are mainly three reasons for this massive HCV transmission in this mass campaign. First, patients were subjected to many injections. Second, sterilization techniques were extremely poor. Finally extensive mistakes, including reuse of equipment ${ }^{(30,31)}$. Focusing on adherence of studied patients to oral Sovaldi treatment regimen, near to one-fifth of studied $\mathrm{CHCV}$ patients (18.8\%) showed poor adherence to treatment. The most mentioned causes of poor adherence of studied CHCV patients were having many medications to take followed by thinking that the treatment is not useful, then being afraid of side effects $(58.1 \%, 41.9 \%$, and $22.6 \%$ respectively). These findings were in accordance with the results of four studies conducted to assess patients' references related to HCV treatment. They found that the most important patient-relevant outcome was overall treatment efficacy followed by risk of adverse events ${ }^{(32-34)}$. Concerning the effect of oral Sovaldi treatment regimen on biochemical parameters of studied $\mathrm{CHCV}$ patients it was found that there was a significant reduction in the median level of both ALT and AST ( 43 and 37 before treatment versus 24 and 26 after treatment), $\mathrm{P}<0.001$. Also significant reduction in the mean hemoglobin level from $12.47 \pm 1.73$ before starting treatment to $11.82 \pm 1.76$ twelve weeks after treatment was noticed, $P<0.001$. This finding was also supported by another study which reported that anemia is among the most commonly mentioned side effects of patients treated with RBV and SOF(34). In agreement with the current study finding a previous study conducted in Egypt illustrated that treatment of HCV patients with SOF-DCV with or without RBV was prematurely discontinued in only $1.5 \%$ of patients mostly due to hematological complication and decompensation(35). HRQoL aims to assess disabilities and effectiveness related to diseases. SF36 is a generic health instrument that was used for the evaluation of HRQoL and also in clinical trials to study the effect of chronic disease on HRQoL (35). Concerning the results of the use of SF-36Q in the present study, it was found that the overall median value of SF-36Q items of the studied patients was 53.19 indicating an impairment in HRQoL. Regarding the various domain items of the SF-36 Q, role limitations due to emotional problems recorded the highest median value (100.0) among all studied CHCV patients followed by the median value of physical functioning (80.0), social functioning (75.0), health change (75.0) and pain (65.0). All these values indicate good HRQoL in these domains. On the other hand, the studied patients recorded the lowest median values in the following domains: energy/fatigue (40.0), emotional well-being (48.8), role limitations due to physical health, and general health perception equally (50.0 for each). These median values indicated poor HRQoL in these domains. Except for role limitation due to emotional problems, this finding is nearly consistent with a study carried out in Taiwan which revealed that antiviral-treated $\mathrm{CHC}$ patients experienced a marked decrease in scores on 6 scales of SF-36Q espe- 
cially in the vitality, role physical, and emotional limitation scales with average scores $(49.07 \pm 22.87,37.50 \pm 44.36$ and $45.35 \pm$ 47.03 respectively). The average score of the physical status was the highest with a score of $78.33 \pm 20.29^{(20)}$. Concerning the present results of the use of CLDQ to assess HRQoL of studied patients, it was found that the overall mean value of CLDQ items was $(4.59 \pm 1.28)$ indicating fair HRQoL. The highest mean values (best $\mathrm{HRQOL})$ were for activity domain (5.81 \pm $1.46)$, systemic symptoms $(5.05 \pm 1.46)$, then abdominal symptoms (4.49 \pm 1.88$)$, and emotional function $(4.48 \pm 1.56)$. The lowest mean values (worst HRQoL) were for the worry domain $(3.64 \pm 2.36)$ and fatigue domains $(4.41 \pm 1.55)$. These results contradicted the study conducted in China 2019, which showed that the WO dimension had the highest score in all CLDQ domains among the studied patients ${ }^{(27)}$. But was consistent with both Taiwan and China study results regarding the scores of FA and EF dimensions of CLDQ which was found to be relatively low among the six dimensions ${ }^{(20,27)}$. Regarding the correlation between overall scores and various domains scores of SF-36Q items and CLDQ items of studied CHCV patients, it was found that scores of almost all domains of SF-36Q were positively correlated with that of CLDQ domains which were consistent with the study conducted in Taiwan 2014, which showed that all SF-36Q domains significantly correlated with all scores of CLDQ domains $(r>0.20)^{(36)}$. and also, with other previous reports(37-39). Moreover, the present study showed that the magnitude of the correlation between FA and EF subscales of CLDQ and SF-36Q scales was the highest. These findings concurred also with the result of the Taiwan study which indicated that fatigue is the most important factor leading to differences in functioning and well-being in CHCV patients under antiviral treatment (36).

\section{Conclusion}

The overall median value of SF-36Q indicated a poor HRQoL, while the overall mean value of CLDQ reflected fair HRQoL. The highest scores were for activity, systemic and abdominal symptoms domains while the lowest was for worry and fatigue. A significant positive correlation was found between the majority of SF-36Q individual domain scores and both CLDQ and the total scores. Raising the awareness of $\mathrm{HCW}$ and family members of patients about CHCV (disease nature, impact of the disease and its treatment on all aspects of the patient's life) and declare their crucial role for relieving much of the patient's suffering and helping them to comply with the treatment and cope with disease burden is recommended.

Funding: This research did not receive any grants from any funding agencies.

\section{Conflicts of interest: None}

Availability of data and material: The data that support the findings of this study are available from the corresponding author upon request.

\section{References}

1. Petruzziello A, Marigliano S, Loquercio $G$, et al. Global epidemiology of HCV infection: An update of the distribution and circulation of hepatitis $C$ virus genotypes. WJG 2016; 22(34):7824-40.

2. World Health Organization (WHO). Hepatitis C. Geneva, Switzerland: WHO; 2016.

3. Denniston $M M$, Jiles RB, Drobeniuc J, et al. Chronic hepatitis $C$ virus infection in the United States, National Health and Nutrition Examination Survey 2003 
to 2010. Ann Intern Med 2014; 160(5):293-300.

4. El Malky M, El Gahsh N, Atia MM. The Effectiveness of Nursing Intervention Program on Emotional Distress, SelfEfficacy, and Liver Enzymes Among Hepatitis C Virus Patients Undergoing Antiviral Treatment Therapy (Sovaldi Medication). Am J Nurs Sci 2016; 5(3):72-84.

5. World Health Organization (WHO). WHO welcomes Egypt's support to 14 African countries in their fight against hepatitis C. Geneva, Switzerland: WHO; 2019.

6. Kouyoumjian SP, Chemaitelly H, AbuRaddad LJ. Characterizing hepatitis C virus epidemiology in Egypt: systematic reviews, meta-analyses, and meta-regressions. Sci Rep 2018; 8(1):1661.

7. Yahia M. Global health: a uniquely Egyptian epidemic. Nature 2011; 474 (7350):S12-3.El-Zanaty F, Way A. Demographic and Health Survey. Cairo, Egypt: Egypt Demographic and Health Survey; 2014.

8. El-Akel W, El-Sayed MH, El Kassas M, et al. National treatment program of hepatitis C in Egypt: hepatitis C virus model of care. J Viral Hepat 2017; 24(4):262-7.

9. Malebranche $M$, King $D$, Leonard J. Descriptive epidemiology of hepatitis C in individuals referred for specialized HCV care in Newfoundland and Labrador, 1996-2014. Canadian Liver J 2018; 1(3):107-14.

10. El-Zanaty F, and Way A. Knowledge and prevalence of hepatitis C. Cairo, Egypt: Egypt Demographic and Health Survey; 2009.

11. El-Ghitany EM. Hepatitis C Virus Infection in Egypt: Current Situation and Future Perspective. J High Instit Public Health 2019; 49(1):1-9.

12. Domagalski K, Pawłowska M, Tretyn A, et al. Impact of IL-28B polymorphisms on pegylated interferon plus ribavirin treatment response in children and adolescents infected with $\mathrm{HCV}$ genotypes 1 and 4. Eur J Clin Microbiol Infect Dis 2013; 32(6):745-54.

13. Martin NK, Vickerman P, Dore GJ, et al. Prioritization of HCV treatment in the direct-acting antiviral era: An economic evaluation. J Hepatol 2016; 65(1):17-25.

14. Asselah T, Boyer N, Saadoun D, et al.. Direct-acting antivirals for the treatment of hepatitis C virus infection: optimizing current IFN-free treatment and future perspectives. Liver Int 2016; 36(Suppl 1):47-57.

15. Armstrong AR, Herrmann SE, Chassany $O$, et al. The International development of PROQOL-HCV: An instrument to assess the health-related quality of life of patients treated for Hepatitis C virus. BMC Infect Dis 2016; 16(1):1-11.

16. Raison CL, Demetrashvili M, Capuron L, et al. Neuropsychiatric adverse effects of interferon-alpha: recognition and management. CNS Drugs 2005; 19(2):105-23.

17. Lam BP, Jeffers $T$, Younoszai $Z$, et al. The changing landscape of hepatitis $C$ virus therapy: focus on interferon-free treatment. Therap Adv Gastroenterol 2015; 8(5):298-312.

18. Younossi ZM, Guyatt G, Kiwi M, et al. Development of a disease-specific questionnaire to measure healthrelated quality of life in patients with chronic liver disease. Gut 1999; 45(2):295-300.

19. Chang SC, Yang SS, Chang CC, et al. Assessment of health-related quality of life in antiviral-treated Taiwanese chronic hepatitis C patients using SF-36 and CLDQ. Health Qual Life Outcomes 2014; $12: 97$.

20. Strickland GT, Elhefni $H$, Salman $T$, et al. Role of hepatitis $C$ infection in chronic liver disease in Egypt. Am J Trop Med Hyg 2002; 67(4):436-42.

21. Gorman BS, Primavera LH, Allison DB. Program for estimating effect sizes, statistical power, and sample sizes. Educ Psychol Meas 1955; 55(5):773-6.

22. Younossi ZM, Kiwi ML, Boparai N, et al. Cholestatic liver diseases and health- 
related quality of life. Am J Gastroenterol 2000; 95(2):497-502.

23. Martin LM, and Younossi ZM. Healthrelated quality of life (HRQL) in chronic liver disease. Dig Liver Dis 2005; 37(11):819-20.

24. Abdulmohsen SA, Coons SJ, Draugalis $J R$, et al. Translation of the RAND 36item health survey into Arabic. Santa Monica, CA, USA: RAND 1997.

25. Behairy OGA. Health-related quality of life in children with chronic hepatitis $C$. Egypt Pediat Assoc Gazette 2016; 64(3):120-5.

26. Marinelli C, Savarino E, Inferrera M, et al. Factors influencing disability and quality of life during treatment: a cross-sectional study on IBD patients. Gastroenterol Res Pract 2019; 2019:5354320.

27. Zhang H, Ren R, Liu J, et al. HealthRelated Quality of Life among Patients with Hepatitis C Virus Infection: A Cross-Sectional Study in Jianping County of Liaoning Province, China. Gastroenterology Research and practice 2020; 2020.

28. Gamaleldin N, Ramadan A, Bahnassy $M$, et al. Geospatial analysis of hepatitis $\mathrm{C}$ viral infection among blood donors in the main blood banks in Alexandria: A novel application of a public health tool. 28 2016:1-9.

29. Frank C, Mohamed MK, Strickland GT, et al. The role of parenteral antischistosomal therapy in the spread of hepatitis C virus in Egypt. Lancet 2000; 355(9207):887-91.

30. Elgharably A, Gomaa Al, Crossey MM, et al. Hepatitis C in Egypt - past, present, and future. Int J Gen Med 2017; 10:1-6.

31. Fraenkel L, Lim J, Garcia-Tsao G, et al. Examining Hepatitis $C$ Virus Treatment Preference Heterogeneity Using Segmentation Analysis: Treat Now or Defer? J Clin Gastroenterol 2016; 50 (3):252-7.

32. Matza LS, Sapra SJ, Dillon JF, et al. Health state utilities associated with attributes of treatments for hepatitis C. Eur J Health Econ 2015; 16(9):100518.

33. Kauf TL, Mohamed AF, Hauber AB, et al. Patients' willingness to accept the risks and benefits of new treatments for chronic hepatitis $C$ virus infection. Patient 2012; 5(4):265-78.

34. Včev A, Jakab J, Kuna L, et al. HealthRelated Quality of Life in AntiviralTreated Chronic Hepatitis C Patients. In Smolic M, Vcev A, Wu G (eds). Update on Hepatitis C: IntechOpen; 2017. 15970.

35. Omar H, El Akel W, Elbaz $\mathrm{T}$, et al. Generic daclatasvir plus sofosbuvir, with or without ribavirin, in treatment of chronic hepatitis C: real-world results from 18378 patients in Egypt. Aliment Pharmacol Ther 2018; 47 (3):421-31.

36. Chang SC, Yang SS, Chang CC, et al. Assessment of health-related quality of life in antiviral-treated Taiwanese chronic hepatitis C patients using SF-36 and CLDQ. Health Qual Life Outcomes. 2014;12(1):1-8.

37. Fábregas $B C$, de Ávila RE, Faria $M N$, et al. Health-related quality of life among patients with chronic hepatitis C: a cross-sectional study of sociodemographic, sychopathological, and psychiatric determinants. Braz J Infect Dis 2013; 17(6):633-9.

38. Jacobson IM, Cacoub P, Dal Maso L, et al. Manifestations of chronic HCV infection beyond the liver. Clin Gastroenterol Hepatol 2010; 8(12):1017-29. 